\title{
Transcurrencia y mélange tectónica en el área de Sierra Arana (Cordillera Bética, NE de Granada)
}

\section{Transcurrent tectonics and mélange in the Sierra Arana area (Betic Cordillera, NE of Granada)}

\author{
C. Sanz de Galdeano, A.C. López Garrido \\ Instituto Andaluz de Ciencias de la Tierra (CSIC- Univ. Granada). Facultad de Ciencias. Univ. de Granada. 18071, Granada. \\ Email: csanz@ugr.es, aclopez@ugr.es
}

\section{RESUMEN}

En el área de Sierra Arana las fallas transcurrentes dextrorsas forman un conjunto de largas y estrechas bandas tectónicas de dirección E-O, varias de las cuales están rellenas por sedimentos oligo-aquitanienses y cretácicos encajados entre carbonatos jurásicos. Estas bandas forman una "estructura en flor", en cuya parte superior, materiales cortados por las fallas cayeron sobre sedimentos oligo-aquitanienses, formándose una mélange tectónica. La zona de crestas de Sierra Arana corresponde a un gran anticlinal invertido vergente al sur. Los materiales situados directamente al S de Sierra Arana, bien se les denomine Subbético muy interno, bien Dorsal, parecen mostrar la transición paleogeográfica del Subbético al Complejo Maláguide.

Palabras clave: Fallas transcurrentes; mélange tectónica; Dorsal Bética; Subbético; complejo Maláguide.

\section{ABSTRACT}

In the Sierra Arana area, dextral transcurrent faults form a set of long and narrow E-W tectonic bands, some of which are filled by Oligo-Aquitanian and Cretaceous sediments deeply squeezed among Jurassic carbonates. These bands form a "flower structure" which higher blocks, cut by the faults, fallen over Oligo-Aquitanian sediments, forming a tectonic mélange. The crest zone of Sierra Arana indicates the position of a great reversed south verging anticlinal. The elements situated directly to the south of Sierra Arana, are attributed to a very internal Subbetic or to the Dorsal, and seem to correspond to the paleogeographic passage from the Subbetic to the Malaguide Complex.

Keywords: Transcurrent faults; tectonic mélange; Betic Dorsal; Subbetic; Malaguide Complex.

\section{Introducción}

La Cordillera Bética además de pliegues y cabalgamientos muestra un importante desarrollo de estructuras transcurrentes que han dejado una notoria impronta en diversos sectores. Así, existe un gran corredor de fallas transcurrentes de dirección NNE-SSO desde Murcia a Cabo de Gata, pasando por Alhama de Murcia y Lorca (Bousquet, 1979; Larouziére et al., 1988; Martínez Díaz, 1998, etc.). También se describen en la Zona Externa (Van de Fliert et al., 1980; de Smet, 1984, de Ruig et al.,

Recibido el 8 de abril de 2016 / Aceptado el 21 de septiembre de 2016 / Publicado online el 24 de noviembre de 2016

Citation / Cómo citar este artículo: Sanz de Galdeano, C. \& López Garrido,A.C. (2016). Transcurrencia y mélange tectónica en el área de Sierra Arana (Cordillera Bética, NE de Granada). Estudios Geológicos 72(2): e055. http://dx.doi.org/10.3989/egeol.42468.415.

Copyright: () 2016 CSIC. This is an open-access article distributed under the terms of the Creative Commons Attribution-Non Commercial (by-nc) Spain 3.0 License. 
1987...), en la Zona Interna, formando el corredor de las Alpujarras (Sanz de Galdeano et al., 1985; Martínez Martínez et al., 2006), y en el contacto entre las zonas Interna y Externa (Martín Algarra, 1987; Crespo, 2008; Balanyá et al., 2008; Sanz de Galdeano, 2012; Sanz de Galdeano \& López Garrido, 2012 y 2013; Sanz de Galdeano et al., 2015). Una visión de conjunto la dio Sanz de Galdeano (1983).

En el conjunto de los sectores del contacto entre las zonas Interna y Externa es precisamente el menos conocido el que se encuentra directamente al sur de Sierra Arana. Allí se ha citado la presencia de fallas de salto en dirección, pero el mayor énfasis se pone en la existencia de cabalgamientos hacia el $\mathrm{N}$ y el S (Balanyá, 1984), cuando, a nuestro juicio, constituye el mejor ejemplo de tectónica transcurrente de todo el contacto de las zonas Internas y Externas. A la vez, y debido a esa tectónica, se puede establecer su conexión genética con una mélange tectónica allí existente. Esto es algo no conocido hasta ahora.

Por ello, el objetivo del presente trabajo es la descripción y discusión de estas estructuras del área de Sierra Arana. También, con el fin de relacionar los dominios geológicos implicados, se hace una breve discusión de la posible paleogeografía, sin entrar en profundidad pues para ello se requiere una mayor amplitud, a la escala de la Cordillera Bético-Rifeña.

\section{Antecedentes}

Los primeros trabajos que incluyen a la zona en estudio (Brouwer, 1926; Staub, 1926; Blumenthal, 1927; Van Bemmelen, 1927) atribuyeron el conjunto de Sierra Arana al Subbético, considerando a este como la posible cobertera despegada de la Zona Interna. Blumenthal \& Fallot (1935) fueron los primeros autores que trabajaron específicamente en el área de Sierra Arana y la atribuyeron al Subbético. Señalaron la existencia del anticlinal de Sierra Arana, algo tan solo aceptado, y descrito, en un trabajo posterior (Pérez-López, 1986a), quizás porque esa área se sitúa en el límite de cuatro hojas 1:50.000 y viene a ser un sector "marginal" de cada uno de ellos.

Aldaya (1966) estudió el sector de Cogollos Vega Peñón de la Mata (es decir, el sector occidental del área ahora estudiada) e indicó que la parte septentrional, la de Sierra Arana propiamente dicha, se debe relacionar con el Subbético, y la meridional podría ser la cobertera del Maláguide. García-Dueñas \& González Donoso (1970) estudiaron ese mismo sector y atribuyeron sus materiales al Subbético Interno.

Fueron Durand-Delga \& Foucault (1968) quienes indicaron la similitud de las series mesozoicas y terciarias situadas al sur de Sierra Arana con las de la Dorsal Rifeña. De ahí vino la definición de la Dorsal Bética como un nuevo elemento paleogeográfico y su separación del Subbético. Foucault \& Paquet (1970) dividieron el sector del S de Sierra Arana en varias unidades. Señalaron la importancia de cizallamientos subhorizontales (cabalgamientos de la Zona Interna trasladada hacia el N). Foucault (1976), al igual que lo hizo Aldaya (1966), relacionó las unidades de la Dorsal con el Maláguide, del que serían su cobertera e indicó la posibilidad de la existencia de una tectónica transcurrente.

García-Dueñas \& Navarro Vila (1976 y 1979) describieron la tectónica de escamas de la Dorsal (aceptaron la atribución a la Dorsal de la parte $\mathrm{S}$ de Sierra Arana), y diferenciaron dos unidades, cada una de ellas formada por varias escamas. La inferior es la que llamaron Cañamaya y a la superior Despeñadero. Balanyá (1984) analizó la estructura y evolución geológica del área situada directamente al sur de Sierra Arana, lo que se consideraba la Dorsal. Destacó la importancia de la estructura en escamas, vergentes al norte, después plegadas y retrovergentes en fallas inversas y desplazamientos transcurrentes dextrorsos, en particular la falla de Almuéjar, que separa la Dorsal del complejo Maláguide. Señaló la similitud de los sedimentos del Oligoceno superior -¿Aquitaniense? de la Dorsal con los de la unidad de La Mora (una de las "unidades de las Ventanas"), y a su vez con los equivalentes del Subbético, si bien en estos últimos no se observan restos procedentes de la Zona Interna.

Al norte de Sierra Arana Comas et al. (1986) describieron la existencia de olistostromas (sobre todo grandes cuerpos -incluso kilométricos- de dolomías y calizas jurásicas) embalados en arenas y limos del Oligoceno-Mioceno inferior, Aquitaniense, situados en el Subbético. Interpretan que la Dorsal del S de Sierra Arana está formada por escamas vergentes al N. Al tiempo se preguntaron si no existía una gran proximidad entre el Subbético Medio, al norte, el Subbético Interno en Sierra Arana y las unidades de la Dorsal, pues tienen características estratigráficas similares en muchos aspectos, con la diferencia 
de que, al igual que señaló Balanyá (1984), en el Paleógeno subbético no se observan clastos de origen metamórfico heredados de la Zona Interna. En el mismo año, Pérez López (1986b) hace una buena síntesis de la estratigrafía y la evolución sedimentaria de la unidad de Sierra Arana.

Lupiani Moreno \& Soria Mingorance (1988) en el área de Cogollos Vega distinguieron la Dorsal, dividida en interna y externa (equivalentes respectivamente a las unidades de Despeñadero y Cañamaya). La tectónica de ese sector correspondería fundamentalmente a cabalgamientos y pliegues. Al igual que en los dos últimos trabajos anteriormente citados, introdujeron un contacto de separación de unidades tectónicas entre el Oligoceno-Mioceno inferior de la Dorsal y el Subbético, aun cuando en anteriores trabajos (García Dueñas \& González Donoso, 1970; López Garrido \& Orozco, 1970) este contacto se consideraba simplemente una discordancia estratigráfica, lo cual tiene importancia para la reconstrucción paleogeográfica.

\section{Situación geológica}

En el área en estudio están presentes parte de las zonas Interna y Externa de la Cordillera Bética (Fig. 1). La Externa corresponde a la cobertera mesozoica y terciaria de parte de los bordes oriental y meridional del Macizo Ibérico. Se divide en Prebético y Subbético según su mayor o menor proximidad a la Meseta. Sierra Arana, que comprende el sector norte de la zona de estudio, se atribuye al Subbético y, de acuerdo con la nomenclatura de García Dueñas (1967, 1968 y 1969), corresponde al Subbético Interno (esta nomenclatura divide el Subbético en Externo, Medio e Interno, según su mayor o menor proximidad al antepaís, la Meseta).

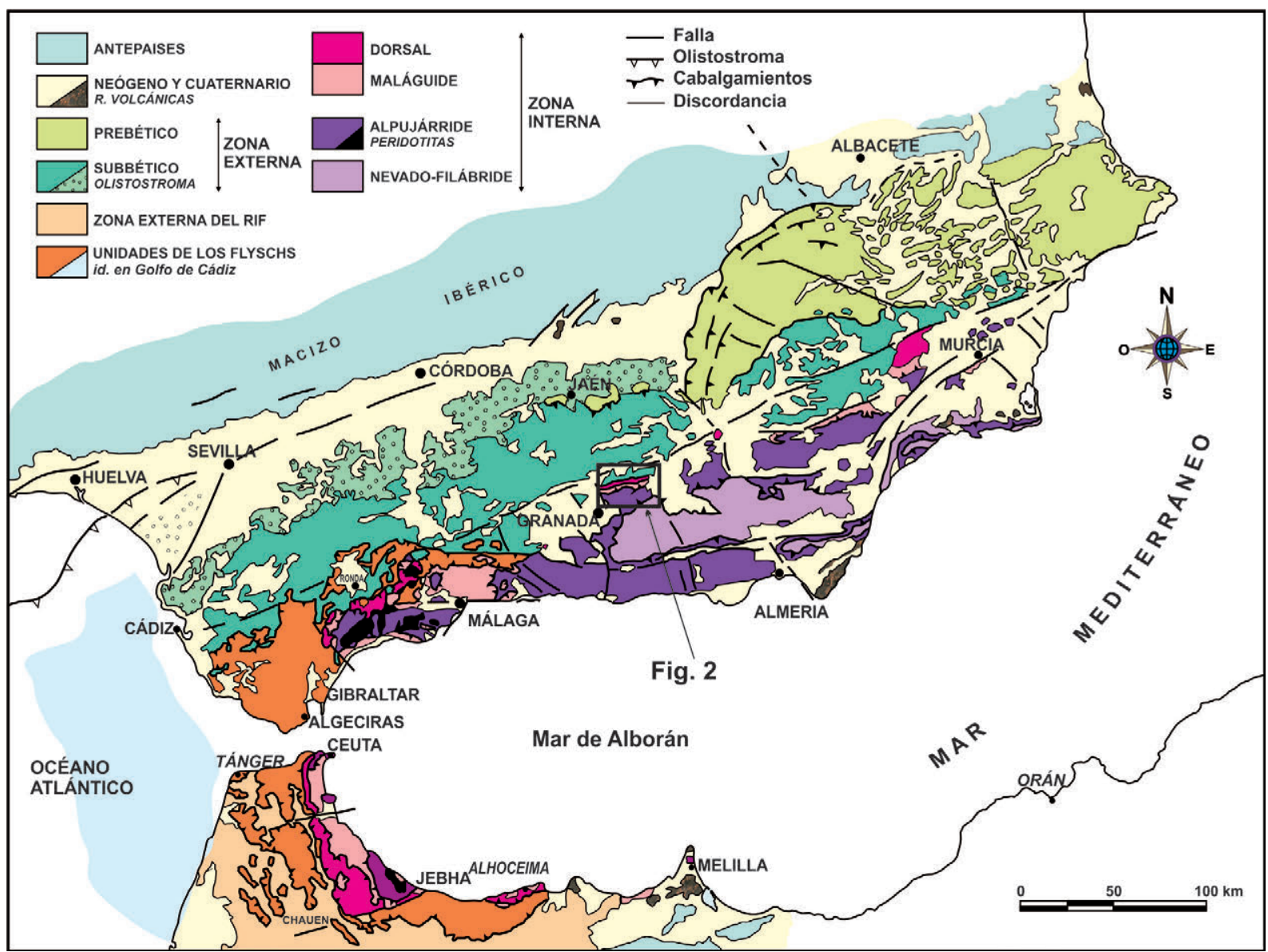

Fig. 1.-Mapa general de la Cordillera Bética, y de parte del Rif, en el que se encuadra el área estudiada. El recuadro marca la posición de la figura 2. 
La Zona Interna de la Cordillera Bética está formada por tres complejos superpuestos tectónicamente, más la Dorsal. El complejo inferior, formado por rocas metamórficas, es el Nevado-Filábride (Fig. 1) y no aflora en el área estudiada, pero se muestra un poco en la parte SE de la Fig. 2. Encima se sitúa el complejo Alpujárride, generalmente metamórfico, formado por varias unidades tectónicas. Al mismo se atribuyen las "unidades de las Ventanas" (Figs. 2 y 3 ) que no son metamórficas o lo son tan solo en parte y que afloran en ventanas tectónicas, de ahí su nombre, bajo unidades alpujárrides (Sanz de Galdeano et al., 1995a, b y c). Sobre el Alpujárride se encuentra el complejo Maláguide, con poco o escaso metamorfismo, formado sobre todo por secuencias lutíticas paleozoicas y una cobertera, en muchos puntos poco conservada, de sedimentos mesozoicos y terciarios. Al Maláguide se asocia la Dorsal ya aludida en los antecedentes y del que sería parte de su cobertera. La Dorsal ha sido también denominada "Unidades Frontales" (Martín-Algarra et al., 20014), o formando parte de las unidades de este nombre, situadas "al frente" de la Zona Interna.
La estructuración, y metamorfismo, alpinos de la Zona Interna se produjo desde finales del Cretácico hasta el Mioceno medio. Ya para el OligocenoAquitaniense se había producido el cabalgamiento del Maláguide sobre el Alpujárride y de este sobre el Nevado-Filábride, si bien, la deriva de la Zona Interna hacia el O, durante el Mioceno inferior, reajustó y generó en algún caso, las unidades tectónicas.

En la Zona Externa durante el Cretácico se formaron algunas discordancias que parecen reflejar las deformaciones que se iniciaban en la Zona Interna. Esto es más visible en el Terciario, así en el Oligoceno-Aquitaniense que es rico en arenas. $\mathrm{Su}$ principal deformación se produjo durante el Mioceno inferior producida por el empuje de la Zona Interna hacia el O y OSO (Boillot et al., 1984; Sanz de Galdeano, 1990 y 1997). Este fue el momento en el que se formaron las principales estructuras transcurrentes de dirección ENE-OSO de la Cordillera Bética antes citadas.

En el área en estudio (área de Sierra Arana) de N a S, se encuentra el Subbético Interno (Sierra Arana o unidad de Sierra Arana), la Dorsal dividida en numerosas unidades, escamas o láminas cortadas

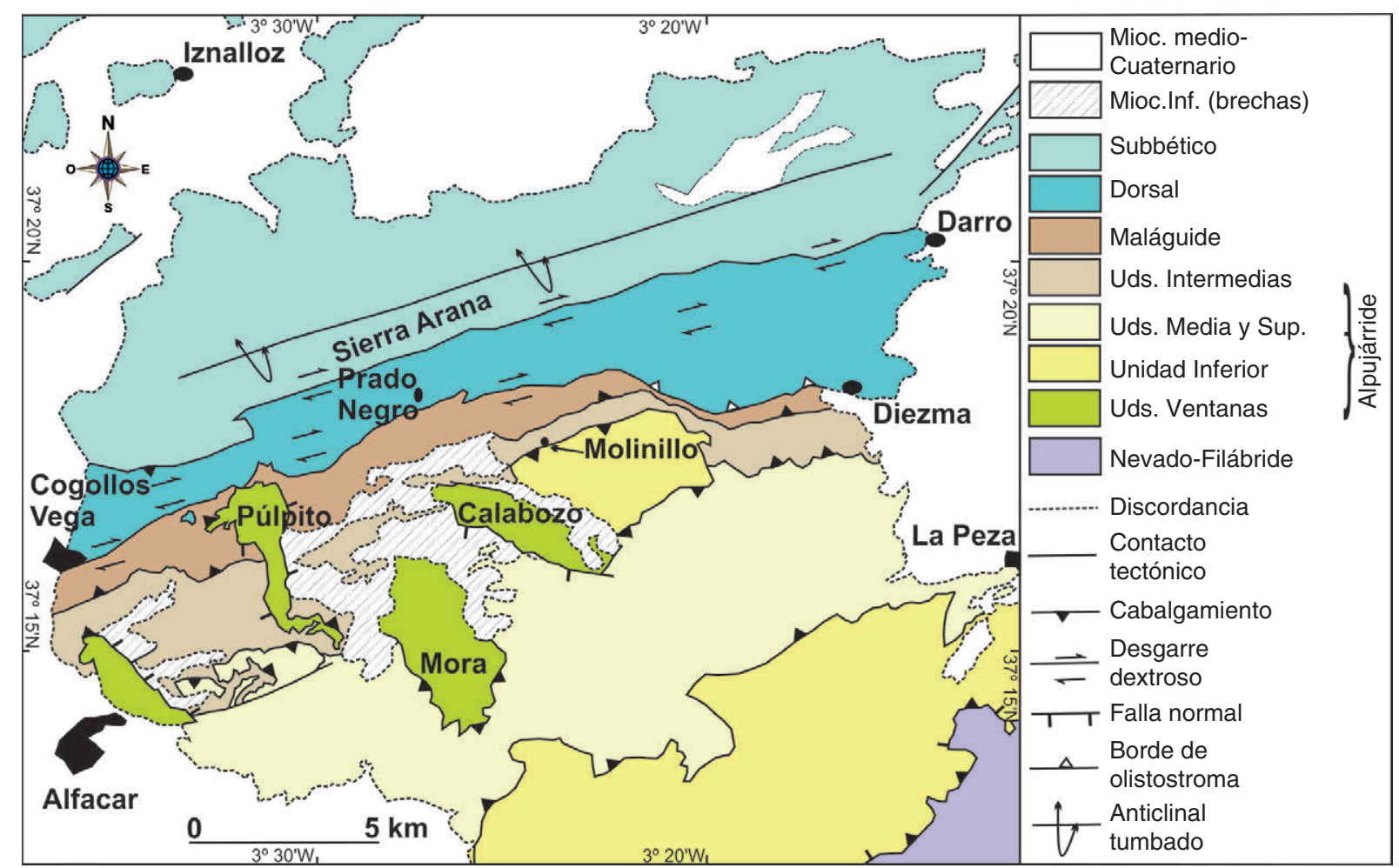

Fig. 2.-Esquema geológico del entorno de Sierra Arana. Su posición se marca en la Fig. 1. 


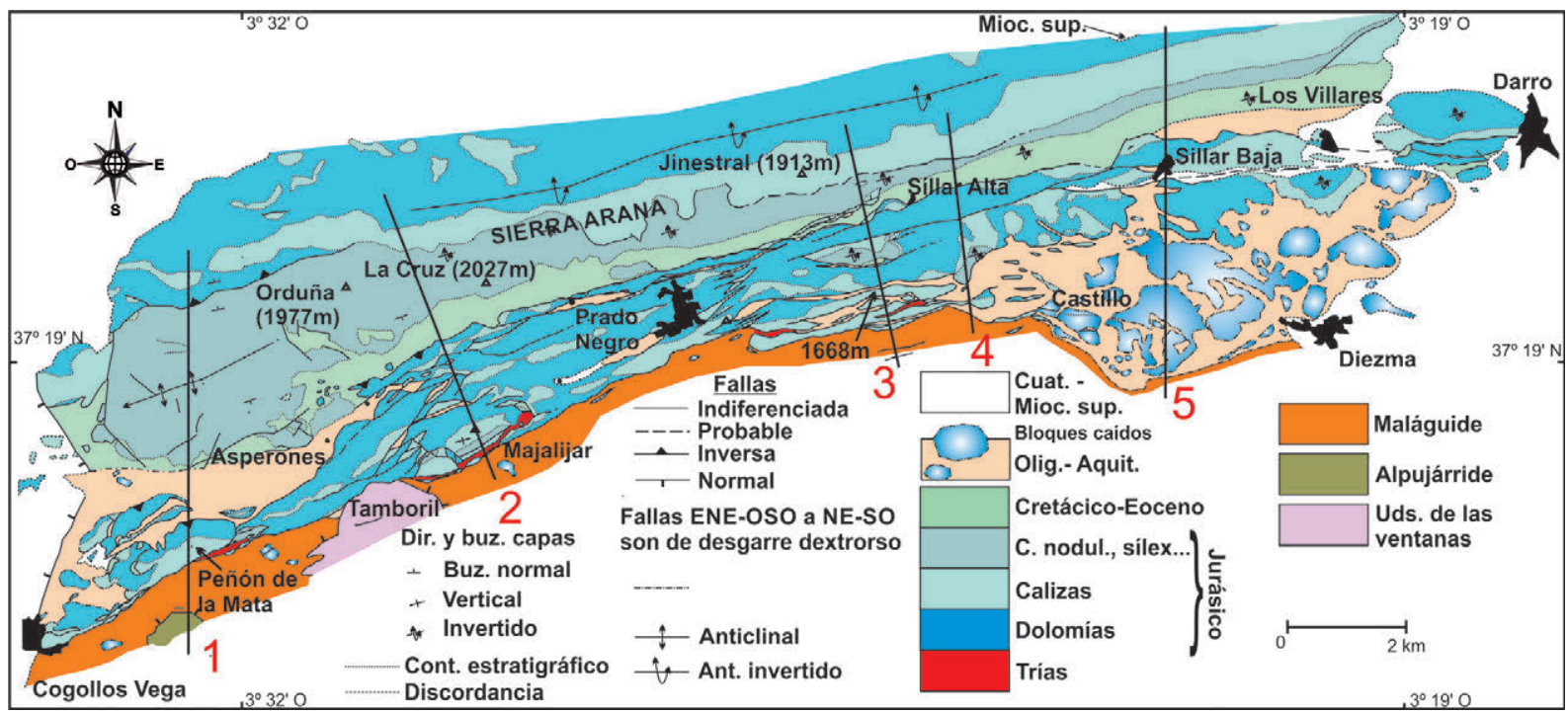

Fig. 3.-Mapa geológico simplificado de Sierra Arana y su prolongación meridional (ocupa la parte central de la Fig. 2). Se indica la posición de los cortes de la figura 7 .

por fallas transcurrentes y los complejos Maláguide y Alpujárride. Además hay restos de una mélange tectónica que se sitúa sobre los tres primeros dominios señalados.

\section{Principales rasgos estratigráficos}

Tan solo se van a indicar los rasgos imprescindibles para que el lector tenga idea de las series litológicas; también se señalan algunos rasgos 1lamativos anteriormente no descritos. Descripciones bastante detalladas se pueden encontrar en trabajos antes citados.

La sucesión de Sierra Arana comienza por arcillas, limos y arenas de tonos rojizos del Trías. Se observan fuera del área estudiada justo al NO de la Fig. 3, y a ellos se asocian rocas volcánicas básicas que también alcanzan las dolomías superiores.

Las dolomías forman un grueso paquete de 300 o más metros de potencia. Suelen estar formadas por estratos de un espesor del orden del metro, aunque estén internamente laminadas. En algunos puntos, hacia la base, se intercalan niveles margosos. PérezLópez et al. (1993) dataron como Sinemuriense inferior (del Liásico inferior, o sea, Jurásico inferior) el que llaman término II de las dolomías. Cabe preguntarse si su término I, el más bajo en tránsito a las arcillas, limos y arenas rojizos, pudiera -al menos en parte- pertenecer al techo del Trías. Sobre las dolomías aparecen calizas claras cuya potencia es del orden de 200-300m. Su estratificación generalmente es más fina que la de las dolomías. Son del Jurásico inferior, Lías.

Encima existen términos predominantemente calizos, localmente con intercalaciones margosas. Destaca, sobre todo al O, la presencia de abundante sílex negro, en nódulos redondeados y/o adaptándose a las capas de calizas. Tienen importantes variaciones laterales de espesor. Así, al NE de Sierra Arana, no alcanzan más de $60 \mathrm{~m}$, pero al O de la misma, en el área de Cañá Larga y Pico de Orduña, el espesor es al menos del orden de $250 \mathrm{~m}$. Corresponden al resto del Lías, quizás hasta la base del Dogger.

El Dogger y el Malm están formados por calizas tableadas, finas, en muchos casos nodulosas -rojas o no-, localmente brechoides, en muchos puntos con sílex negro hacia la base y rojo y verde hacia el techo. Hay que señalar que localmente se produce una notoria silicificación de las capas calizas, en particular entre el Collado del Agua y el Pico Orduña. La potencia de estas calizas varía desde pocos metros al NE de Sierra Arana, a quizás unos 40m al SO. Por ello, dada la escala de las figuras, este tramo se ha puesto junto a las calizas anteriores.

Encima existen margas y margocalizas claras del Cretácico inferior, que localmente conservan unos $100 \mathrm{~m}$ de espesor. Sobre ellas localmente se observan 
niveles margosos y margocalizos de tonos asalmonados que suelen estar muy deformados. Abarcan el Cretácico superior y el Paleoceno. Estos tramos se muestran de forma conjunta en las figuras. Dada su tectonización no se puede dar un espesor fiable, aunque se sabe que en el Subbético pueden alcanzar varios cientos de metros de espesor.

Por último aparecen arcillas, arenas, y finos conglomerados de tonos pardo-rojizos datados del Oligoceno superior-Aquitaniense. Son discordantes sobre el Cretácico-Paleoceno.

Las secuencias de la Dorsal, es decir, de los materiales que se encuentran situadas directamente al $\mathrm{S}$ de Sierra Arana formando multitud de unidades, son bastante parecidas a las de esa unidad. Los materiales triásicos aparecen en algunas bandas entre fallas y están formados por lutitas, arenas y conglomerados finos, junto con algunos yesos. El color predominante es el rojo. Aunque parecidos a materiales equivalentes del Subbético, son similares a los del complejo Maláguide, con los que en algunos puntos se muestran en continuidad. Es interesante mostrar que al SE del pico Majalijar se observa que a techo de los materiales triásicos aparecen dolomías carniolares que hacen el tránsito estratigráfico a las dolomías antes citadas.

Las dolomías son semejantes a las de Sierra Arana y sobre ellas también afloran las calizas inferiores. Encima los términos del Lías superior -base del Dogger tienen mayor variedad que los de Sierra Arana, también localmente con sílex negro. Desarrollan en algunos puntos calizas nodulosas rojas en términos liásicos, del Carixiense-Domeriense (véanse las publicaciones citadas en antecedentes), y presentan algunos términos de margas, margocalizas y calizas tableadas.

El Dogger y el Malm son fundamentalmente calizos, a techo nodulosos, rojos o no. Es interesante señalar que desarrollan localmente brechas y conglomerados intraformacionales. Ya en la unidad de Sierra Arana se observaron algunos niveles de brechas muy localizados, pero en la Dorsal son más abundantes. Se ven por ejemplo al E del Peñón de la Mata, pero sin duda donde mejor se observan es directamente al sur del pico de Majalíjar. Allí existen al menos $30 \mathrm{~m}$ de capas de conglomerados nutridos de restos de la misma formación, con cantos incluso decimétricos. Están bien expuestos pues se encuentran en posición prácticamente vertical, al igual que los materiales inferiores.

En los términos altos del Malm existe también sílex de tonos rojos y verdes, localmente muy abundante, similar al de la unidad de Sierra Arana.

Allí donde se conserva el Cretácico y el Paleoceno, generalmente en bandas tectonizadas, no se observan diferencias con el de Sierra Arana. Existen además algunos afloramientos calizos del Eoceno, con nummulites. Los materiales del Oligoceno-Aquitaniense son los mismos que los de Sierra Arana, si bien contienen restos de liditas y algunas rocas que parecen heredadas de las series paleozoicas maláguides.

El complejo Maláguide está formado predominantemente por lutitas paleozoicas, carboníferas, sobre las que se depositaron discordantemente sedimentos triásicos. En estos últimos señalamos, además, la presencia de conglomerados tipo Verrucano y algunos niveles de dolomías tableadas intercaladas.

Los materiales alpujárrides incluidos en la Fig. 3 corresponden a mármoles dolomíticos. En cuanto a los materiales del cerro Tamboril, atribuido a una de las "unidades de las Ventanas", son parecidos a las secuencias de la Dorsal, aunque ocupan una posición tectónica muy diferente.

Discordante sobre la unidad de Sierra Arana existe un afloramiento de areniscas, calizas bioclásticas y margas del Mioceno superior (estos materiales son abundantes al $\mathrm{N}$ del área estudia, fuera ya de la misma). Además, hay muchos derrubios, depósitos aluviales y coluviales, junto con terrenos cubiertos por suelos.

\section{Estructura}

Son tres los rasgos fundamentales de la estructura del sector: el anticlinal tumbado de Sierra Arana, la tectónica transcurrente y la mélange tectónica. Además existen diversas fallas posteriores.

\section{El anticlinal tumbado de Sierra Arana}

Es de dirección aproximada E-O y recorre longitudinalmente esta sierra. El flanco norte del anticlinal es normal, con poco buzamiento, mientras que su flanco $\mathrm{S}$ está invertido con vergencia al S. En no pocos sitios, así en el cerro de la Cruz, la inversión 


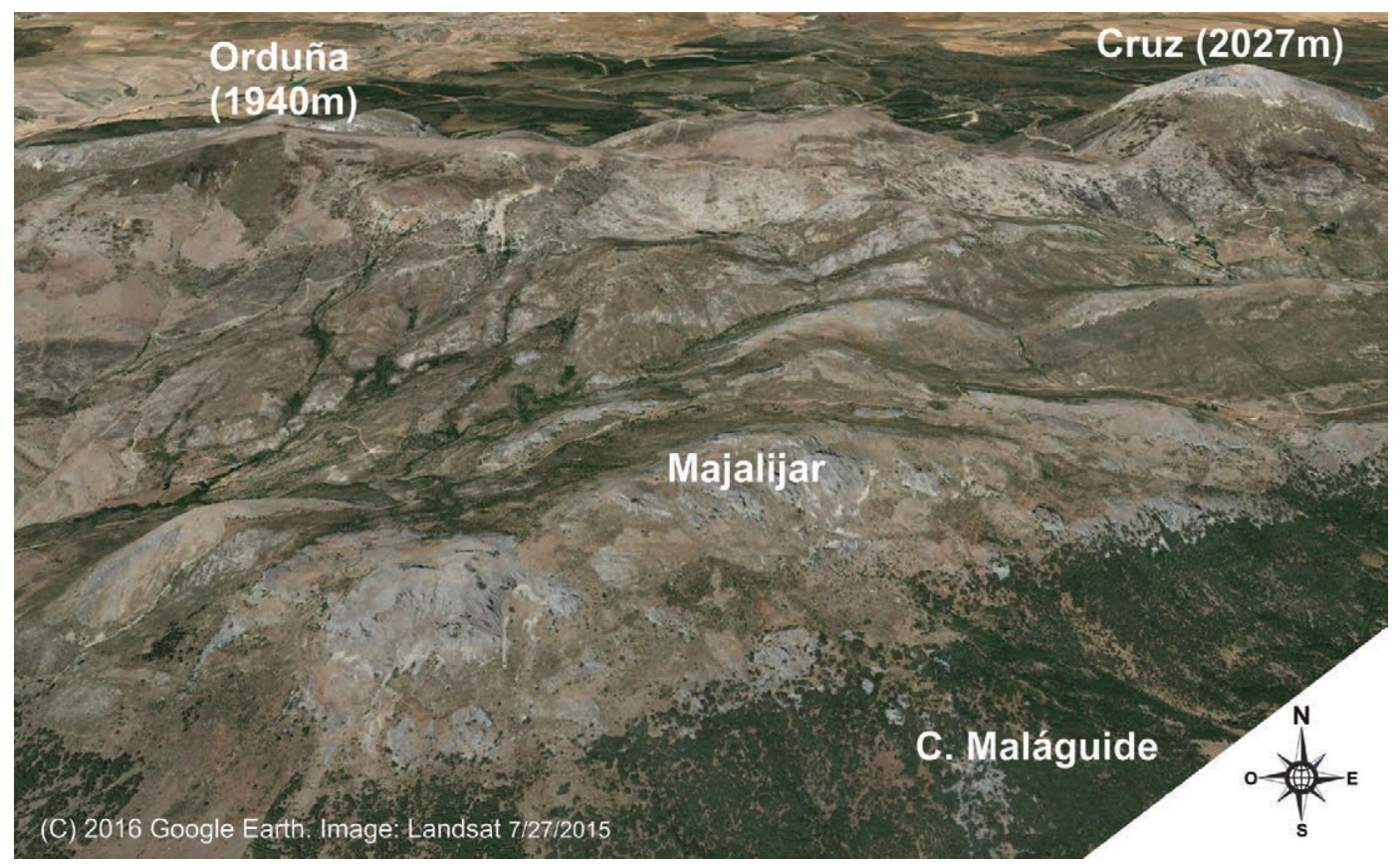

Figs. 4.-Vista parcial del área estudiada en la que se puede observar la disposición en estrechas bandas situadas entre fallas transcurrentes. Al O y al NO del pico Majalijar se pueden ver estructuras de mega-"almendras".

se acompaña de cabalgamiento, de manera que las calizas inferiores cabalgan sobre materiales más jóvenes. Más al O la inversión pasa a ser una gran falla inversa que va desde la terminación occidental de Sierra Arana hasta la cueva del Agua (GarcíaDueñas \& González Donoso, 1970), a lo largo del valle denominado Cañá Larga, cerca ya del Pico Orduña.

Acompañan al anticlinal otras fallas locales (Pérez López, 1986a), algunas de las cuales son difíciles de ver pues corresponden a despegues. De ahí que en varios sitios no se pueda determinar si se está ante un simple contacto estratigráfico o si es tectónico. Algunas de estas fallas repiten localmente la serie estratigráfica.

\section{La tectónica transcurrente}

El conjunto de estructuras que desde el $\mathrm{O}$ (en Cogollos Vega) se extiende hasta el E (en Darro), corresponde fundamentalmente a fallas transcurrentes (Figs. 3 y 4). Generalmente se han denominado escamas tectónicas, pero sus contactos son en muchos casos verticales y, sobre todo, las estrías, acanaladuras, pliegues de arrastre y cualquier otra estructura que indique su cinemática muestran movimientos dextrorsos puros o bien oblicuos con componente dextrorso. Localmente los afloramientos de superficies con estriaciones y acanaladuras son grandes, de decenas de metros. Aunque estas estructuras menores ligadas a las fallas aparecen en muchos puntos, destacamos algunos de ellos: a) en las paredes meridionales del Peñón de la Cruz (no es el cerro de la Cruz) a $1 \mathrm{~km}$ al ESE de Síllar Alta, corresponde a la unidad de Sierra Arana, b) en el borde sur del cerro de Almuéjar, 0,5km al SE de Prado Negro, en el contacto de la Dorsal con el Maláguide, c) $400 \mathrm{~m}$ al SE del pico Majalijar (1878m) en la Dorsal, cerca del contacto con el Maláguide, y d) entre la localidad de Cogollos Vega y el Peñón de la Mata, donde muchas de las almendras calizas implicadas en las fallas van acompañadas de materiales triturados del Cretácico y Terciario, totalmente estirados en la dirección de las fallas.

Como se ha indicado, las fallas son generalmente verticales, lo que no impide que cabeceen dando localmente geometrías compatibles con fallas inversas e, incluso, normales, aunque esto último más raramente.

Quizás el rasgo más llamativo de estas fallas transcurrentes sea la existencia de largas bandas verticales de materiales del Cretácico (Fig. 5a) y sobre todo del 
(a)

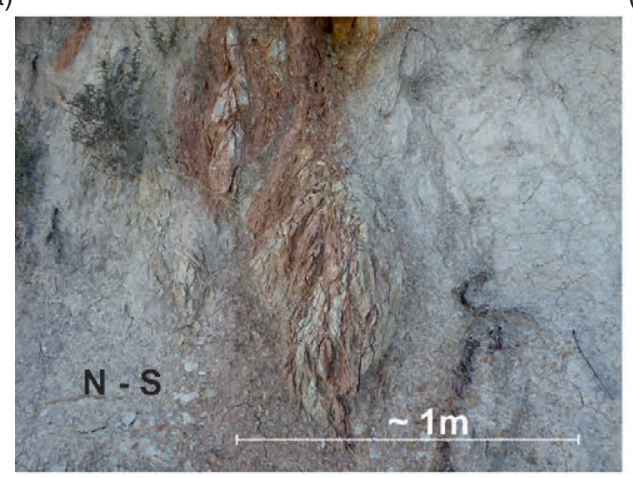

(c)

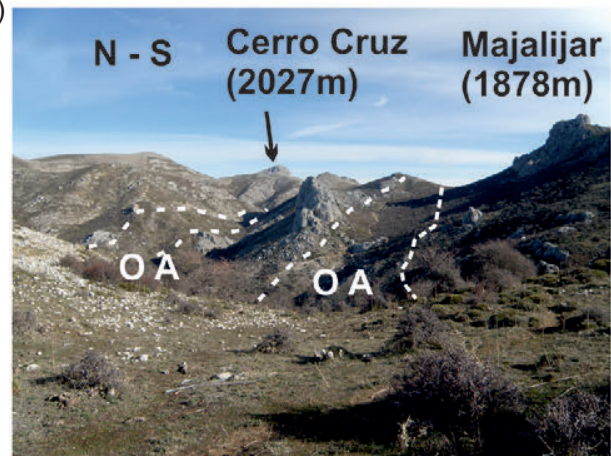

(b)



(d)

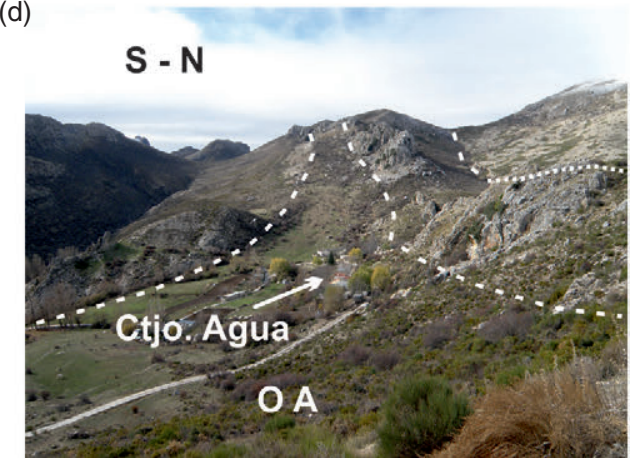

Fig. 5.-a) vista en corte vertical de una de las numerosísimas estructuras de cizalla, en este caso en materiales del Cretácico superior. b) vista de la ladera oriental del Jorobado. c) bandas al $\mathrm{N}$ del Pico Majalijar. d) vista al O del cortijo de Aguas. Las fallas se indican en líneas blancas a trazos. Son todas prácticamente verticales, aunque la perspectiva da buzamientos aparentes. OA: sedimentos oligoaquitanienses en bandas.

Oligo-Aquitaniense metidas entre cuerpos de calizas y dolomías. En la Fig. 3 se indican las más visibles, pero existen algunas más cuyo espesor y corrida son menores. En esas bandas las imbricaciones de materiales del Cretácico y del Oligo-Aquitaniense son abundantes, pero en la citada figura no se pueden reflejar.

En algunos puntos se ha podido ver la base de estas bandas. Corresponden a estrechas zonas de rampas con estriaciones y acanaladuras. En estas rampas el sentido de desplazamiento de los materiales incluidos en las bandas no ha resultado uniforme, unas veces indican desplazamiento de techo hacia el E y otras veces hacia el $\mathrm{O}$.

Los cuerpos rocosos cortados por las fallas en algunos casos están verticales o tienen buzamientos próximos a la vertical (Fig. 5b, c y d y Fig. 6a, b y c), en otros tienen poco buzamiento y los cortes de las fallas son muy patentes (Fig. 7), pero además -sobre todo hacia el E- se invierten, tal como señaló Balanyá (1984) (Fig. 7, cortes 3 y 4). Se tiene en esos casos estructuras invertidas cortadas por el $\mathrm{N}$ y por el S. La inversión resulta patente gracias a la posición relativa de las dolomías y con las calizas; de estas calizas y las nodulosas y de estas últimas con las margas del Cretácico inferior.

A lo largo del recorrido de las bandas se observan abundantes estructuras arrosariadas, a modo de grandes almendras tectónicas, formadas durante el desplazamiento de las fallas. Son fácilmente observables las calizas que han quedado pinzadas entre dolomías, o entre cualquier otro material. También se observan "esquirlas" de materiales cretácicos cogidas entre fallas y, a mayor escala, las propias bandas del Oligo-Aquitaniense. Alguna de las estructuras de aspecto sigmoidal son observables en Google Earth (así en el punto $37^{\circ}, 18^{\prime} 10^{\prime \prime} \mathrm{N} / 3^{\circ} 30^{\prime} 29^{\prime \prime} \mathrm{O}$ ), en la que se puede incluso deducir el sentido de desplazamiento.

Estas fallas transcurrentes no se limitan a lo que se considera la Dorsal, sino que también afectan a parte de la propia unidad subbética de Sierra Arana, por ejemplo al NO de la cortijada de Síllar Alta (más al N, en el Subbético Medio, ya fuera del 
(a)

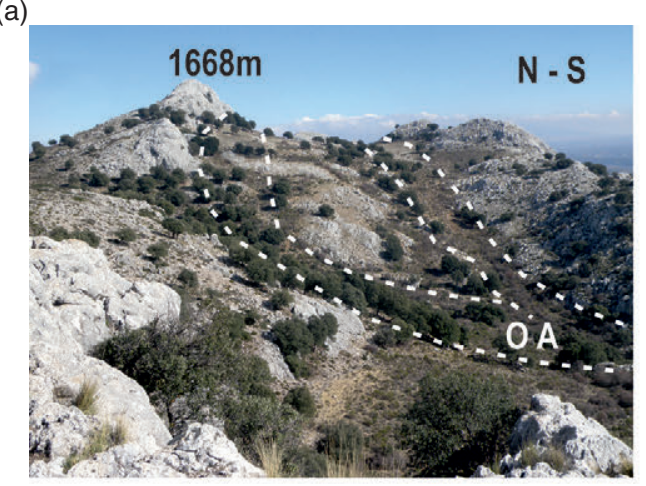

(c)

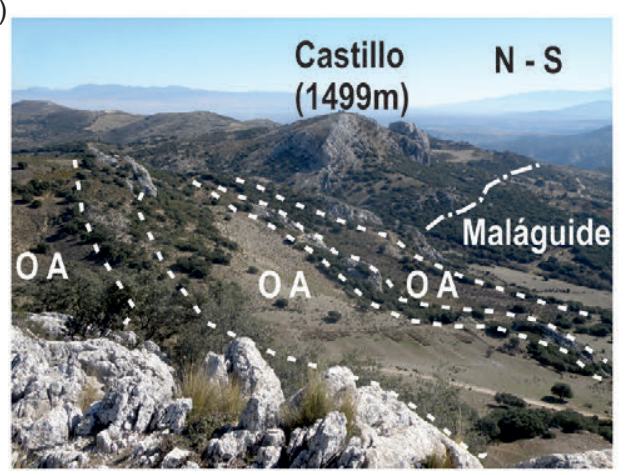

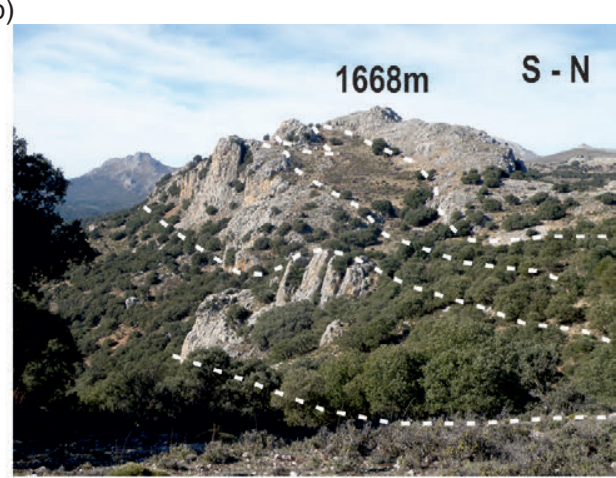

(d)

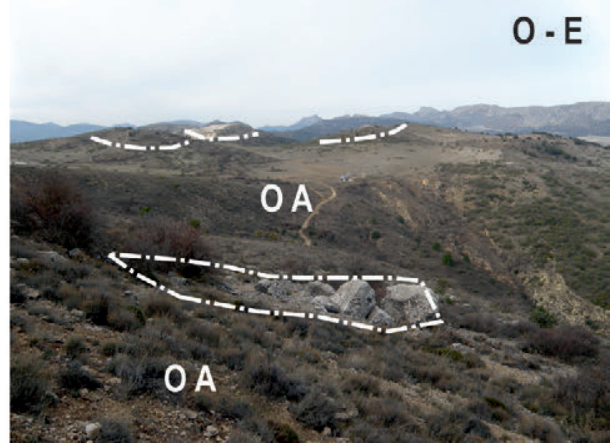

Fig. 6.-a) bandas tectónicas al O del pico 1668 (su posición se marca en la Fig. 3). Dejan en medio una "almendra" de calizas. b) vista oriental del sector del pico 1668. Se ve el cierre de la "almendra" de calizas. c) bandas situadas más al E del pico 1668 y, más lejos, vistas del mélange tectónica sobre el complejo Maláguide. d) Vista parcial del mélange tectónica, en el que hay pequeños olistolitos calizos. Las fallas se indican en líneas blancas a trazos. OA: sedimentos oligo-aquitanienses.

área estudiada hay fallas transcurrentes paralelas - Sanz de Galdeano, 1983 y 2004; Martín Algarra et al., 1988). También, además de afectar al contacto de la Dorsal con el Maláguide (falla de Almuéjar de Balanyá, 1884), dentro del propio complejo Maláguide se han observado fallas paralelas, así al NE del cortijo del Molinillo, que sin duda forma parte del mismo conjunto de fallas transcurrentes (se señalan en la parte $\mathrm{S}$ del corte 3 de la Fig. 7).

No todas las fallas del área estudiada son de dirección E-O a ENE-OSO. Hay algunas transversales que cortan a las anteriores y otras, menores, de cualquier dirección.

\section{La mélange tectónica}

En la parte oriental del área estudiada, sector de Síllar Baja-Darro y Diezma, afloran predominantemente materiales oligo-aquitanienses, entre los que hay grandes bloques, incluso kilométricos, de dolomías, calizas, junto a otros generalmente más pequeños de margas cretácicas e incluso lutitas triásicas.
Destaca en estos bloques el desorden tectónico, sin ninguna pauta estructural (Figs. 3, 6d, cortes 4 y 5 de la Fig. 7, y Fig. 8). Se sitúan sobre, o más bien entre, los sedimentos oligo-aquitanienses.

Por este mismo desorden tectónico no se ha abordado en el presente trabajo la cartografía interna de los bloques. Información al respecto puede verse en el mapa geológico de La Peza (García-Dueñas \& Navarro-Vila, 1979). En cualquier caso sus elementos corresponden con los descritos en la serie litológica de la Dorsal. No se observan rasgos evidentes de sedimentación y resedimentación ligados al emplazamiento de los bloques.

\section{Otros rasgos tectónicos}

Sierra Arana está cortada bruscamente al O por fallas casi N-S a NO-SE que hunden su bloque occidental, cubierto actualmente por sedimentos neógenos y cuaternarios de la cuenca de Granada. Estas fallas tienen cientos de metros de salto vertical y, sin duda, en el bloque hundido esconden la continuación 


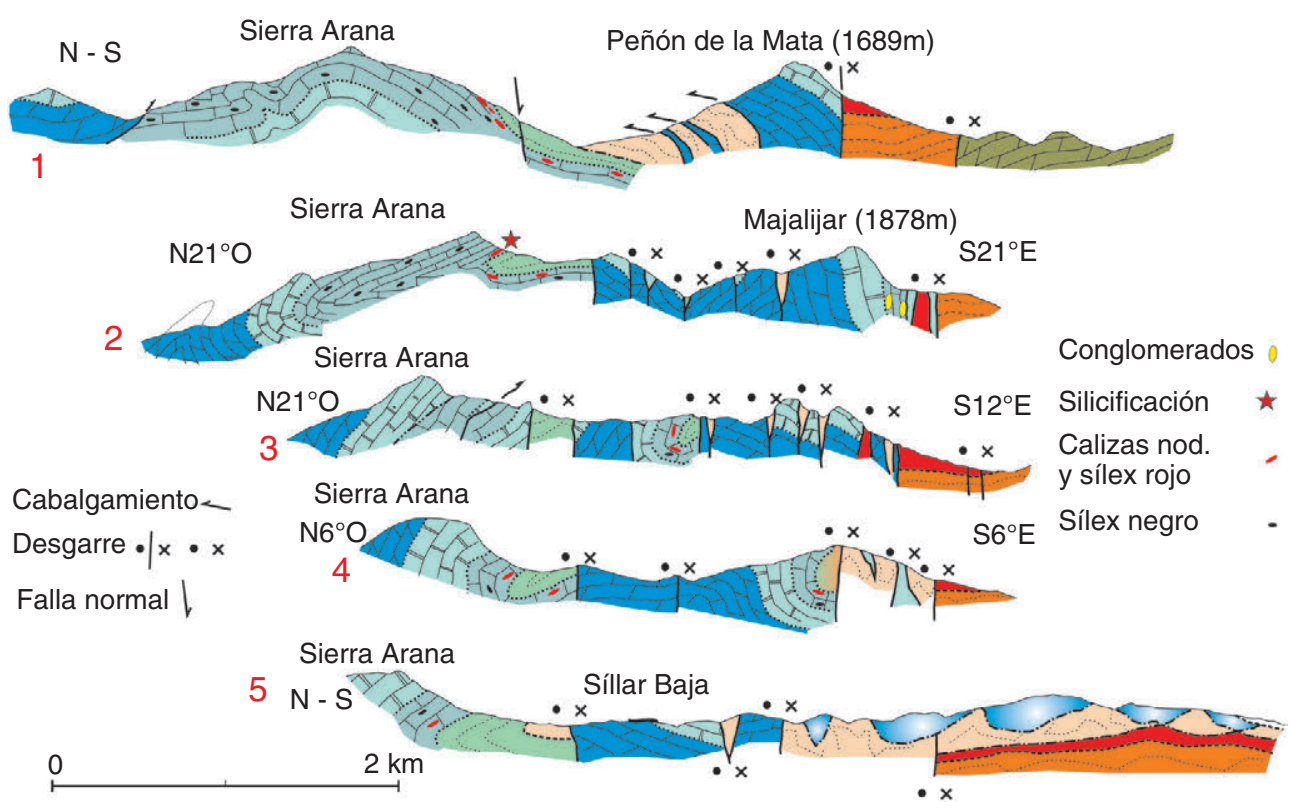

Fig. 7.-Cortes geológicos del área de Sierra Arana. Los colores coinciden con los de la Fig. 3. Su posición se marca en la figura 3.

de las estructuras antes descritas. Estas fallas han producido además un basculamiento del área de Sierra Arana, levantándola en su borde occidental. Esto explica que las mayores alturas de esta sierra se alcancen hacia el $\mathrm{O}$, mientras que los relieves descienden progresivamente hacia el E. En el borde oriental no existe una falla equivalente a la del occidental, sino que la estructura general se hunde progresivamente. Aquí la continuidad de la estructura deja de verse por estar cubierta por sedimentos neógenos y cuaternarios de la cuenca de Guadix-Baza.

\section{Discusión e interpretaciones}

De todo el contacto existente entre las zonas Interna y Externa es quizás el sector de Sierra Arana el más espectacular. Es el que muestra un mayor número de fallas transcurrentes (aunque su número varía de una transversal a otra) y en el que las estrechas y alargadas bandas de materiales oligo-aquitanienses, o de otras edades, están mejor representadas. Es el sector que da unas estructuras que más propiamente pueden ser comparadas con las "flower structures" (Harding, 1974 y 1985) ligadas a fallas transcurrentes (wrench faults). En la Fig. 9 se ha hecho una reconstrucción a partir del corte 3 de la Fig. 7, incluyendo la parte erosionada de la estructura. Su parte inferior no es visible, aunque pensamos que disminuirá el número de fallas, al ir progresivamente coalesciendo hacia abajo. Hacia el techo es más fácil hacer la reconstrucción, pues se puede tomar parte de lo observado en otros cortes, sobre todo los más orientales.

En las estructuras en flor de Harding (ops. cit.) se observa cómo hacia arriba las fallas tienden a curvarse (véase la Fig. 9), lo que concuerda con las inversiones existentes en el sector de Síllar BajaDarro y, en general, con algunas curvaturas que hacia techo muestran las fallas en varios sectores. La reconstrucción hecha en la Fig. 9, realizada manteniendo aproximadamente los espesores de los materiales cortados en las fallas, es de una flor "neutra", ni positiva ni negativa, pero con una asimetría debida a un cierto levantamiento de la parte meridional.

Si la transcurrencia se combinara con una compresión muy importante posiblemente no se hubieran formado las estrechas bandas rellenas de materiales oligo-aquitanienses o triásicos (no habría habido espacio para ello), mientras que si se hubiera combinado con una extensión importante, las bandas no serían tan estrechas. La formación de las bandas se logró además por el hecho de que el desplazamiento de muchas fallas no siempre fue de transcurrencia pura como se ha indicado antes, sino que en no pocos casos fue oblicuo, permitiendo el hundimiento 


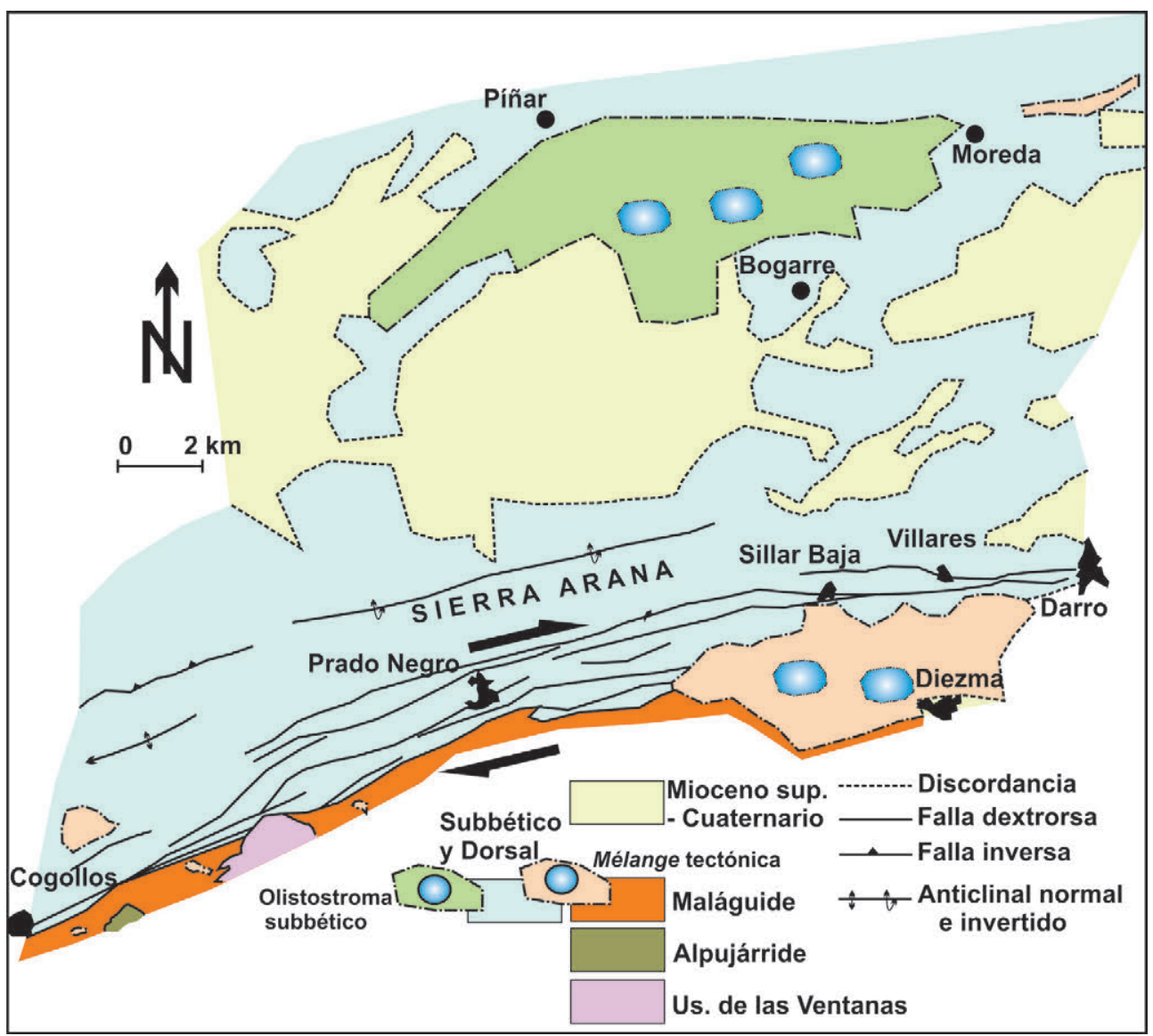

Fig. 8.—Distribución de formaciones olistostrómicas en el entorno de Sierra Arana. Los colores coinciden con los de la Fig. 3.

y la expulsión (con movimientos hacia abajo y hacia arriba) de diferentes materiales. Los desplazamientos relativos entre unos y otros bloques podían variar en velocidad y sentido, lo que hizo que los materiales incluidos en las estrechas bandas muestren desplazamientos de techo hacia el $\mathrm{E}$ o hacia el O según los casos.

En una estructura de tipo flor las fallas tienden a abrirse en abanico hacia la superficie, (Fig. 9). Significa eso que en la parte superior los materiales cortados por las fallas no siguen estando apretados sino que terminan por desprenderse y desplazarse lateralmente quedando encima o entre los sedimentos más jóvenes, y en este caso poco competentes, del Oligoceno-Aquitaniense. Entonces se formó la mélange tectónica.

Es esta evolución de la estructura en flor desde la profundidad a la superficie la que permite establecer la relación genética existente entre las apretadas bandas de fallas y la extraña disposición de enormes bloques desordenados que se encuentra encima, algo que a primera vista no tenía la menor relación.

Actualmente la mélange tectónica está bien conservada en el área de Sillar Baja, Darro y Diezma y eso es debido a que, en su conjunto, Sierra Arana se hunde en esa dirección, mientras que hacia el $\mathrm{O}$, donde está muy levantada, tan solo se conservan algunos pequeños restos "flotando" sobre el Maláguide y el Subbético. La diferencia es debida al diferente grado de erosión.

Antes se ha citado la existencia de olistostromas en áreas relativamente próximas del Subbético (Comas et al., 1986) justo en materiales del OligoAquitaniense (Fig. 8). Pensamos que corresponden al mismo fenómeno que el aquí descrito para la formación de la mélange tectónica. Y se debieron formar bien por las fallas ahora estudiadas, o bien por otras similares situadas dentro del Subbético, dado que es conocida allí su existencia (Sanz de Galdeano, 1983 y 2004). 


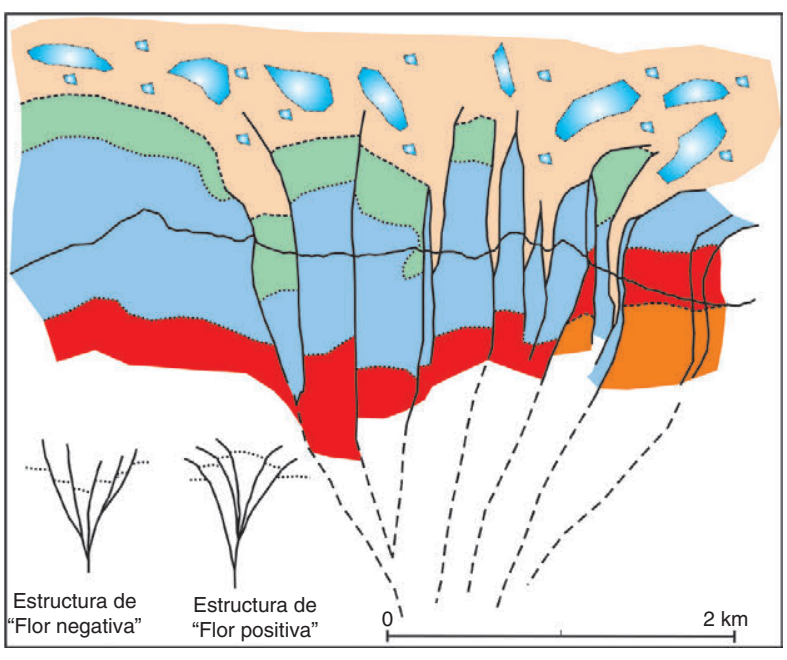

Fig. 9.-Modelo de estructura en flor propuesto para las fallas transcurrentes de Sierra Arana. Se utiliza el corte 3 de la figura 7. Los colores coinciden con los de la Fig. 3

En la Cordillera Bética existen grandes olistostromas en la cuenca del Guadalquivir (Perconig, 1960-62), interpretación que se extendió a zonas más amplias (Pérez López \& Sanz de Galdeano, 1994, entre otros autores). Este enorme olistostroma se formó a partir del Mioceno medio y en el superior. Por el contrario, la mélange tectónica ahora estudiada y los olistostromas citados por Comas et al., 1986) son mucho más reducidos y anteriores en edad.

En los antecedentes del artículo se han mostrado las discrepancias existentes con respecto a la atribución paleogeográfica de los materiales situados entre la unidad subbética de Sierra Arana y el Maláguide. Los primeros artículos los consideraron del Subbético, pero a partir de Durand-Delga \& Foucault (1968) se atribuyeron a la Dorsal Bética, comparándola con la Dorsal Rifeña. Ambas dorsales tienen el rasgo común de formar un conjunto de unidades situadas al frente de la Zona Interna, pero ya Martín Algarra (1987) pensó en la existencia de dos dorsales que no tuvieron originalmente posiciones totalmente equivalentes.

En el caso del área estudiada ahora, los elementos de la Dorsal Bética se muestran ligados al complejo Maláguide (comparten estrictamente los mismos sedimentos triásicos), fueron parte de su cobertera. Pero también presentan enormes similitudes con el Subbético Interno representado en la unidad de Sierra Arana. Los cambios litológicos y de espesor entre sus series son relativamente pequeños, algo que dentro de la propia unidad subbética de Sierra Arana ocurre. De ahí que la discusión de si se trata de elementos de la Dorsal o del Subbético Interno pueda ser superflua, pues quizás se esté ante algo que corresponde al Subbético interno y que a la vez pasa al complejo Maláguide. En principio se puede considerar que son unidades que marcan el tránsito de un dominio a otro.

Se ha señalado antes que el sector del Tamboril (Fig. 3) es de difícil interpretación. En ese monte afloran materiales atribuidos a una de las "unidades de las Ventanas", en concreto la que se llama del Púlpito cuya serie litológica es bastante parecida a la de la Dorsal. Además, hay un punto allí en el que no se ve ningún contacto tectónico entre las dolomías de la Dorsal y las del Tamboril, a pesar de que deben estar cortadas por la falla de Almuéjar de Balanyá (1984). De ahí que se pongan en continuidad tal como lo hicieron Blumenthal \& Fallot (1935) y Foucault (1976). Pero existen dos razones para separarlas: a). Las "unidades de las Ventanas" se sitúan bajo otras unidades alpujárrides y estas a su vez bajo el Maláguide, mientras que la Dorsal está sobre este complejo. b). En el sector del Tamboril, las dolomías de la Dorsal, situadas al N del Tamboril, están acompañadas, en parte de la base del relieve, por calizas liásicas. Si estas calizas están en su posición original muestran que el contacto con las dolomías del Tamboril, situadas directamente al S, no es normal, pues estas últimas corresponden a niveles bajos (se ven bien las capas y su disposición) y las que tienen las calizas corresponderían a niveles altos.

Estas razones garantizan que el contacto sea tectónico. Y si las calizas no están en su posición original (de hecho parecen cogidas en una estirada "almendra" tectónica) el contacto también es tectónico. A esto se suma que allí mismo hay también restos de materiales oligo-aquitanienses pinzados. Todo esto avala que el contacto sea tectónico, aun cuando la separación entre las dolomías no se vea sobre el terreno. Esta conclusión que es de poca importancia para el presente trabajo sí tiene interés para la reconstrucción paleogeográfica que aquí solo se esboza. Es en un trabajo de este último tipo donde cabe justificar las posibles transiciones señaladas anteriormente.

Autores anteriores, así Balanyá (1984), distinguen varias etapas de deformación necesarias para formar 
la estructura, unas de cabalgamientos con vergencias al $\mathrm{S}$ y al $\mathrm{N}$ y otra de transcurrencia. En nuestro caso esta reconstrucción no la podemos mostrar con tanta claridad pues la etapa de transcurrencia domina al conjunto, afectando desde el Maláguide a la unidad de Sierra Arana. A su vez, el plegamiento del Subbético próximo al área estudiada, tiene vergencia predominante al S (así el gran anticlinal de Sierra Arana). Y no tenemos datos que, con claridad, nos permitan separar la transcurrencia de la compresión aproximadamente N-S.

Por ello, grosso modo, las etapas serían las siguientes (sin tener en cuenta la estructuración previa de los complejos Maláguide y Alpujárride): Los materiales más jóvenes que se observan implicados en la fallas transcurrentes del área de Sierra Arana, y en la mélange tectónica ligada, son los del OligoAquitaniense. Por eso, la transcurrencia debió tener lugar en el Mioceno inferior, parte del Aquitaniense y Burdigaliense (correspondería en buena medida con el paroxismo burdigaliense del Subbético según lo denominó Hermes, 1985), sin duda en parte continuado a lo largo del Mioceno medio. Pero en ese periodo no podemos separar la transcurrencia de la formación de pliegues, dado que en parte, al menos, pudieron ser coetáneos. Posteriormente, ya en el Mioceno superior es cuando se formaron las fallas del borde occidental de Sierra Arana, que a su vez la bascularon hacia el E. A esto ha seguido un importante levantamiento regional, ayudado por un rejuego de las fallas últimas citadas.

\section{Conclusiones}

Las fallas transcurrentes verticales o casi verticales son las estructuras dominantes en el área de Sierra Arana. Los numerosos indicadores de dirección y sentido de movimiento observados muestran desplazamientos horizontales a oblicuos, dextrorsos o con componente dextrorso.

Sus movimientos oblicuos han favorecido la formación de largas y estrechas bandas verticales rellenas por materiales oligo-aquitanienses y cretácicos, profundamente encajados entre otras bandas formadas por carbonatos jurásicos.

En su conjunto, la geometría de estas fallas corresponde a una "estructura en flor", que no se muestra ni positiva ni negativa, pero con una cierta asimetría pues su parte sur está algo levantada. Este tipo de estructura favoreció que en su parte alta, al abrirse en abanico, se formaran inversiones localmente importantes. Esto produjo a su vez la caída gravitatoria de elementos cortados por las fallas, los cuales quedaron encajados y dispersos entre los sedimentos oligo-aquitanienses, formándose la mélange tectónica. De este modo se relacionan genéticamente dos tipos de estructuras que aparentemente no tienen relación.

Dado que la erosión ha sido menos profunda en la parte oriental del área de Sierra Arana, allí es donde se conserva mejor la mélange. Al N de Sierra Arana hay una formación comparable que pudo formarse en similares condiciones.

Hay que resaltar la existencia de un gran anticlinal tumbado, vergente al sur situado a lo largo de la cresta E-O de Sierra Arana.

La atribución de los elementos situados directamente al sur de Sierra Arana, bien a la Dorsal o al Subbético muy interno, puede ser una discusión innecesaria, pues ambas cosas podrían ser ciertas. Corresponderían a un Subbético muy interno, que a la vez transicionaran a la cobertera del complejo Maláguide, aunque posiblemente la tectónica haya hecho desaparecer algunos de los elementos originalmente existentes.

\section{AGRADECIMIENTOS}

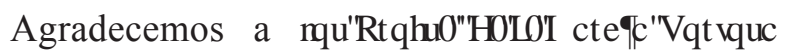
de la UnivHUGDCAde Jaén, \$ [3pUH]/ ySH CGHD 8 QYHHGDAGH Granada y a un LHLRUDOUQIP RISRU VXVacertadas correcciones y VXJ HHQLIDV

\section{Referencias}

Aldaya, F. (1966). Sobre la estructura tectónica del extremo occidental de Sierra Arana y sectores adyacentes (Cordilleras Béticas, provincia de Granada). Acta Geológica Hispànica, 1 (5): 5-8.

Balanyá, J.C. (1984). El Complejo Dorsaliano al Este de Granada: Relaciones estructurales con la Zona Bética y el Subbético Interno. I Congreso Español de Geología, 3: 169-175.

Balanyá, J.C.; Díaz-Azpiroz, M.; Expósito, I.; CrespoBlanc, A. \& Torcal, F. (2008). Asociaciones estructurales de la Alta Cadena (Béticas): un ejemplo de zona de cizalla frágil-dúctil con alto reparto de la deformación. Geotemas, 10: 317-320. 
Blumenthal, M. (1927). Versuch einer tektonischen gliederug der betischen cordilleren von Central, und Sud-West Andalusien. Eclogae Geologicae Helvetiae, 20: 487-592.

Blumenthal, M. \& Fallot, P. (1935). Observations géologiques sur la Sierra Arana entre Grenade et Guadix. Memorias de la Sociedad Española de Historia Natural, 17: 5-74.

Boillot, G.; Montadert, L.; Lemoine, M. \& Biju-Duval, B. (1984). Les marges continentales actuelles et fossiles autour de la France. Masson, Paris, 342 p.

Bousquet, J.C. (1979). Quaternary strike-slip faults in southeastern Spain. Tectonophysics, 52 (1-4): 277-286. http://dx.doi.org/10.1016/0040-1951(79) 90232-4

Brouwer, H.A. (1926). Zur Tektonik der betischen Kordilleren. Geologische Rundschau, 17 (5): 332-336. http://dx.doi.org/10.1007/BF01802785

Comas, M.C.; García-Dueñas, V. \& Navarro-Vilá, F. (1986). Mapa Geológico de España, E: 1:50.000, hoja 992 (Moreda), Memoria. I.G.M.E., Madrid, $51 \mathrm{p}$.

Crespo-Blanc, A. (2008). Recess drawn by the internal zone outer boundary and oblique structures in the paleomargin-derived units (Subbetic Domain, central Betics): An analogue modeling approach. Journal of Structural Geology, 30 (1): 65-80. http:// dx.doi.org/10.1016/j.jsg.2007.09.009

De Ruig, M.J. ; Mier, R.M. \& Stel, H. (1987). Interference of compressional and wrenching tectonics in the Alicante region, SE Spain. Geologie en Mijnbouw, 66: 201-212.

De Smet, M.E.M. (1984). Wrenching in the External Zone of the Betic Cordilleras, Southern Spain. Tectonophysics, 107 (1-2): 57-79. http://dx.doi. org/10.1016/0040-1951(84)90028-3

Durand-Delga, M. \& Foucault, A. (1968). La Dorsale bétique, nouvel élément paléogéographique et structural des Cordillères bétiques au bord Sud de la Sierra Arana (prov. de Grenade, Espagne). Bulletin de la Société Géologique de France, 7 (9): 723-728.

Foucault, A. (1976). Compléments sur la géologie de l'Ouest de la Sierra Arana et de ses environs (province de Grenade, Espagne). Bulletin de la Société Géologique de France, S7-XVIII (3): 649-658. http:// dx.doi.org/10.2113/gssgfbull.S7-XVIII.3.649

Foucault, A. \& Paquet, J. (1970). La structure de l'Ouest de la Sierra Arana (Province de Grenade, Espagne). Comptes Rendus Hebdomadaires de l'Académie des Sciences de Paris, 271: 16-19.

García Dueñas, V. (1967). Unidades paleogeográficas en el sector central de la Zona Subbética. Notas y Comunicaciones del Instituto Geológico y Minero de España, 101-102: 73-100.

García Dueñas, V. (1968). Hipótesis sobre la posición tectónica de la Sierra Arana (Granada). Acta Geológica Hispánica, 3 (2): 29-34.
García Dueñas, V. (1969). Les unités allochtones de la zone Subbétique dans la trasversale de Grenade (Cordillères Bétiques, Espagne). Révue de Géographie physique et de géologie dynamique, 11: 211-222.

García-Dueñas, V. \& González-Donoso, J.M. (1970). Mapa y memoria explicativa de la Hoja 1009 (Granada) del Mapa Geológico nacional a escala 1:50.000. IGME, Madrid, $16 \mathrm{p}$.

García-Dueñas, V. \& Navarro-Vilá, F. (1976). Alpujarrides, Malaguides et autres unités allochtones au Nord de la Sierra Nevada (Cordillères Bétiques, Andalousie). Bulletin de la Société Géologique de France, S7-XVIII (3): 641-648. http://dx.doi.org/10.2113/ gssgfbull.S7-XVIII.3.641

García-Dueñas, V. \& Navarro-Vilá, F. (1979). Mapa Geológico de España, E 1:50.000 ( $2^{\mathrm{a}}$ serie), La Peza (1010), Memoria. I.G.M.E., Madrid, 83 p.

Harding, T.P. (1974). Petroleum Traps Associated with Wrench Faults. American Association of Petroleum Geologist Bulletin, 58 (7): 1290-1304.

Harding, T.P. (1985). Seismic Characteristics and identification of Negative Flower Structures, Positive Flower Structures and Positive Structural Inversion. American Association of Petroleum Geologist Bulletin, 69 (4): 582-600.

Hermes J.J. (1985). Algunos aspectos de la estructura de la Zona Subbética (Cordilleras Béticas, España Meridional). Estudios Geológicos, 41: 157-176. http://dx. doi.org/10.3989/egeol.85413-4709

Larouzière, F.D. de; Bolze, J.; Bordet, P.; Hernández, J.; Montenat, Ch. \& Ott d'Estevou, Ph. (1988). The Betic segment of the lithosperic Trans-Alboran shear zone during the Late Miocene. Tectonophysics, 152 (1-2): 41-52. http://dx.doi.org/10.1016/0040-1951(88) 90028-5

López Garrido, A.C. \& Orozco, M. (1970). Estudio estratigráfico del sector centro-oriental de Sierra Arana (Cordilleras Béticas). Acta Geológica Hispánica, 1 (1): 4-7. http://hdl.handle.net/10261/8011

Lupiani Moreno, E. \& Soria Mingorance, J. (1988). Mapa geológico de España, e: 1:50.000, hoja 1025 (Granada), Memoria. I.G.M.E., Madrid, 74 p.

Martín-Algarra, A. (1987). Evolución geológica alpina del contacto entre las Zonas Internas y las Zonas Externas de la Cordillera Bética. Tesis Universidad de Granada, 1171 p.

Martín-Algarra, A.; Andreo, B.; Balanyá J.C.; Estévez, A.; López-Garrido, A.C.; Martín-Algarra, A.; O’Dogherty, L. \& García-dueñas, V. (2004). Unidades Frontales de las Zonas Internas. In: Vera, J.A. (Ed.). Geología de España. Sociedad Geológica de España \& Instituto Geológico y Minero de España, Madrid, 396-398.

Martín-Algarra, A.; Sanz de Galdeano, C. \& Estévez, A. (1988). L'evolution sédimentaire miocène de la région au nord de la Sierra Arana (Cordillères Bétiques) et sa relation avec la mise en place du bloc 
d'Alboran. Bulletin de la Société Géologique de France, 4 (1): 119-127. http://dx.doi.org/10.2113/ gssgfbull.IV.1.119

Martínez Díaz, J.J. (1998). Neotectónica y Tectónica Activa del sector centro-occidental de la región de Murcia y sur de Almería (Cordillera Bética España). Tesis Universidad Complutense de Madrid, 466 p. http://eprints.ucm.es/1980/

Martínez-Martínez, J.M.; Booth-Rea, G.; Azañón, J.M. \& Torcal, F. (2006). Active transfer fault zone linking a segmented extensional system (Betics, southern Spain): Insight into heterogeneous extension driven by edge delamination. Tectonophysics, 422 (1-4): 159173. http://dx.doi.org/10.1016/j.tecto.2006.06.001

Perconig, E. (1960-62). Sur la constitution géologique de l'Andalousie occidentale, en particulier du bassin du Guadalquivir (Espagne méridionale). In: DurandDelga, M. (Dir.). Livre à la mémoire du Professeur Paul Fallot consacré à l'évolution paléogéographique et structurale des domaines méditerranéens et alpins d'Europe. Société géologique de France, Paris, 229-256.

Pérez López, A. (1986a). Estratigrafía y estructura del sector noroccidental de Sierra Harana (Subbético Interno, Cordillera Bética). Mediterránea, Serie de Estudios Geológicos, 5: 147-156.

Pérez López, A. (1986b). Nuevos datos sobre la estratigrafía y evolución sedimentaria del Mesozoico de la unidad de Sierra Harana (Subbético Interno, Cordillera Bética). Estudios Geológicos, 42 (6): 397-405. http://dx.doi.org/10.3989/egeol.86426770

Pérez-López, A.; Martín-Algarra, A.; Alméras, Y. \& Foucault, A. (1993). Découverte de brachiopodes du Sinémurien dans la Sierra Harana (Subbétique Interne, Cordillères Bétiques, Prov. de Grenade, Espagne): Implications stratigraphiques. Estudios Geológicos, 49 (1-2): 69-75. http://dx.doi.org/10. 3989/egeol.93491-2339

Pérez-López, A. \& Sanz de Galdeano, C. (1994). Tectónica de los materiales triásicos en el sector central de la Zona Subbética (Cordillera Bética). Revista de la Sociedad Geológica de España, 7 (1-2): 141-153. http://hdl.handle.net/10261/29309

Sanz de Galdeano, C. (1983). Los accidentes y fracturas principales de las Cordilleras Béticas. Estudios Geológicos, 39 (3-4): 157-165.

SanzdeGaldeano, C.(1990). Geologic evolution of the Betic Cordilleras in the Western Mediterranean, Miocene to the present. Tectonophysics, 172 (1-2): 107-119. http://dx.doi.org/10.1016/0040-1951(90)90062-D

Sanz de Galdeano, C. (1997). La Zona Interna BéticoRifeña (Antecedentes, unidades tectónicas, correlaciones y bosquejo de reconstrucción paleogeográfica). Colección monográfica. Tierras del Sur, 18. Universidad de Granada, 316 p.
Sanz de Galdeano, C. (2004). Pliegues limitados por fallas en el subbético medio (sector de torre cardela, granada). Geogaceta, 35: 59-61. http://hdl.handle. net/10261/29374

Sanz de Galdeano, C. (2012). Estructuras ligadas al contacto entre las zonas Interna y Externa de la Cordillera Bética al Norte de Málaga. Geotemas 13: 449-452.

Sanz de Galdeano, C.; Delgado, F. \& López Garrido, A.C. (1995a). Unidades alpujárrides y maláguides al NE de Granada (Cordillera Bética). Geogaceta, 18: 27-29. http://hdl.handle.net/10261/29312

Sanz de Galdeano, C.; Delgado, F. \& López Garrido, A.C. (1995b). Estructura del Alpujárride y del Maláguide al NW de Sierra Nevada (Cordillera Bética). Revista de la Sociedad Geológica de España, 8 (3): 239-250. http://hdl.handle.net/10261/29316

Sanz de Galdeano, C.; Delgado, F.; López Garrido, A.C. \& Martín Algarra, A. (1995c). Appartenance alpujarride proposée de l'unité de La Mora au NE de Grenada (Cordillère Bétique, Espagne). Comptes rendus de l'Académie des sciences, Série 2, Sciences de la terre et des planètes, 321 (10): 893-900. http:// gallica.bnf.fr/ark:/12148/bpt6k6410227s/f83.item

Sanz de Galdeano, C. \& López Garrido, A. (2012). The Torcal de Antequera, an example of a structure formed by a large scale dextral transcurrent system. Estudios Geológicos, 68 (2): 189-202. http://dx.doi. org/10.3989/egeol.40679.160

Sanz de Galdeano, C. \& López Garrido A.C. (2013). Tectónica de las sierras penibéticas de Abdalajis y de Huma (provincia de Málaga, España): su relación con el contacto con la Zona Interna. Estudios Geológicos. 69 (2): 133-147. http://dx.doi.org/10.3989/egeol41033.230

Sanz de Galdeano, C.; López Garrido, A.C. \& Andreo, B. ( 2015). The Internal Subbetic of the Velez Rubio area (SE Spain): is it tectonically detached or not? Journal of Geodynamics, 83: 65-75. http://dx.doi. org/10.1016/j.jog.2014.09.009

Sanz de Galdeano, C.; Rodríguez Fernández, J. \& López Garrido A.C. (1985). A strike-slip fault corridor within the Alpujarra Mountains (Betic Cordilleras, Spain). Geologische Rundschau, 74 (3): 641-655. http://dx.doi.org/10.1007/BF01821218

Staub, R. (1926). Gedanken zur Tektonik Spaniens. Vierteljahrsschriften, Naturforschende Gesellschaft in Zürich, 71 (3-4): 196-261.

Van Bemmelen, R.W. (1927). Bijdrage tot de Geologie der BetischeKetensindeprovincieGranada. Tesis doctoral TUDelft. Waltman, Delf, 176 p. http://resolver.tudelft. nl/uuid:3596f09c-c23b-4326-86cf-36988abb5171

Van de Fliert, J.; Graven, H.; Hermes, J.J. \& Smet E.M. de. (1980). On stratigraphic anomalies associated with major transcurrent faulting. Eclogae Geologicae Helvetiae, 73 (1): 223-237. http://dx.doi. org/10.5169/seals-164951 